\title{
Size-Resolved Particle Number and Volume Emission Factors for On-Road Gasoline and Diesel Motor Vehicles
}

George A. Ban-Weiss ${ }^{\mathrm{a}, 1,2}$, Melissa M. Lunden ${ }^{\mathrm{b}}$, Thomas W. Kirchstetter ${ }^{\mathrm{b}}$, Robert A. Harley ${ }^{\mathrm{c},}$

${ }^{a}$ University of California, Dept. of Mechanical Engineering, Berkeley, CA 94720-1740

${ }^{b}$ Lawrence Berkeley National Laboratory, Atmospheric Science Dept., Berkeley, CA 94720

'University of California, Dept. of Civil \& Environmental Engineering, Berkeley, CA 94720-1710

\begin{abstract}
Average particle number concentrations and size distributions from $\sim 61000$ light-duty (LD) vehicles and $\sim 2500$ medium-duty (MD) and heavy-duty (HD) trucks were measured during the summer of 2006 in a San Francisco Bay area traffic tunnel. One of the traffic bores contained only LD vehicles, and the other contained mixed traffic, allowing pollutants to be apportioned between LD vehicles and diesel trucks. Particle number emission factors (particle diameter $\mathrm{D}_{\mathrm{p}}>3 \mathrm{~nm}$ ) were found to be $(3.9 \pm 1.4) \times 10^{14}$ and $(3.3 \pm 1.3) \times 10^{15} \# \mathrm{~kg}^{-1}$ fuel burned for LD vehicles and diesel trucks, respectively. Size distribution measurements showed that diesel trucks emitted at least an order of magnitude more particles for all measured sizes $\left(10<D_{p}<290 \mathrm{~nm}\right)$ per unit mass of fuel burned. The relative importance of $L D$ vehicles as a source of particles increased as $D_{p}$ decreased. Comparing the results from this study to previous measurements at the same site showed that particle number emission factors have decreased for both LD vehicles and diesel trucks since 1997. Integrating size distributions with a volume weighting
\end{abstract}

\footnotetext{
${ }^{1}$ Corresponding author e-mail: georgebw@stanford.edu; phone: +1650 462 1047; fax: +1650 4625968

2 Now at Carnegie Institution, Department of Global Ecology, 260 Panama St, Stanford, CA 94305
} 
showed that diesel trucks emitted $28 \pm 11$ times more particles by volume than LD vehicles, consistent with the diesel/gasoline emission factor ratio for $\mathrm{PM}_{2.5}$ mass measured using gravimetric analysis of Teflon filters, reported in a companion paper.

Keywords: Particle number, motor vehicle, emission, size distribution, tunnel

\section{Introduction}

Particulate matter (PM) emissions from motor vehicles are regulated on a mass basis, whereas particle number emissions are unregulated. Particulate mass and number concentrations show little correlation since most particles are emitted in the nuclei mode (particle diameter $\mathrm{D}_{\mathrm{p}}<50 \mathrm{~nm}$ ), which have negligible mass. There are fewer particles emitted in the accumulation mode $\left(100<\mathrm{D}_{\mathrm{p}}<2000 \mathrm{~nm}\right)$, but these are responsible for the majority of exhaust particulate mass (Kittelson, 1998).

Particles of various sizes and compositions originate from different phases of the combustion process (Kittelson, 1998; Seigneur, 2009). Accumulation mode particles in diesel engines are carbonaceous soot agglomerates, formed early in the combustion process within fuel-rich pockets inside the engine cylinder. Nuclei mode particles are formed in diesel and gasoline engines when hydrocarbons and sulfates, stemming from vaporized lubricating oil and fuel, nucleate as exhaust dilutes and cools. The nuclei mode is highly dependent on the degree of supersaturation of the nucleating species. High concentrations of accumulation mode particles in engine exhaust suppress particle 
formation by scavenging or sorbing precursors needed for nucleation to occur (Kittelson et al., 2006a; Ban-Weiss et al., 2009).

Particle size is important in determining health and environmental impacts of PM. Ultrafine particles $\left(D_{\mathrm{p}}<100 \mathrm{~nm}\right)$ have been identified as a particular concern for human health (Pope et al., 1995; Pope and Dockery, 2006). Laboratory studies have shown that particles that are non-toxic with $\mathrm{D}_{\mathrm{p}} \sim 1 \mu \mathrm{m}$ can be toxic when $\mathrm{D}_{\mathrm{p}} \sim 10 \mathrm{~nm}$ (Seaton et al., 1995; Donaldson et al., 1996). Nuclei mode particles can penetrate deeply into the lung and enter the circulatory system, whereby they may deposit in other vital organs such as the brain or heart (Kennedy, 2007). It has been suggested that adding particle numberbased air quality standards and/or engine emissions limits to the current mass-based limits could help in identifying and reducing adverse health impacts (Kennedy, 2007). Since nuclei mode particles in the atmosphere coagulate with accumulation mode particles in minutes to hours, and can evaporate at even faster time scales (Seigneur, 2009), health effects are especially detrimental to those in close proximity of fresh emissions. The residence time of accumulation mode particles in the atmosphere is $\sim 1$ week, orders of magnitude longer than that of ultrafine particles. Light absorption is stronger than scattering for soot particles in the accumulation mode with important implications on regional visibility degradation and global warming (Ramanathan and Carmichael, 2008).

There is an ongoing debate about the importance of gasoline vs. diesel engines as sources of fine PM (Johnson et al., 2005). Results from a companion paper (Ban-Weiss et al., 
2008 ) indicate that on average, diesel engines emit an order of magnitude more PM mass than gasoline engines, per unit of fuel burned. But the relative importance of gasoline vehicles as a source of PM is higher when considering number rather than mass emissions; the fraction of particles that are emitted in the nuclei mode is higher in gasoline vs. diesel engines (Graskow et al., 1998; Maricq et al., 1999a; Maricq et al., 1999b; Kayes et al., 2000; Johnson et al., 2005). However, variations in sampling protocols, both in terms of driving cycles and PM measurement methods (Ayala et al., 2003), and a lack of definitive "real-world" studies, have made direct comparison of gasoline vs. diesel particle number emissions difficult. Further complications arise due to dilution and atmospheric aging of aerosols; semi-volatile organic compounds that are emitted in the particle-phase from engines can evaporate upon dilution in the atmosphere. These gas-phase species may undergo subsequent photochemical reactions to form secondary organic aerosol (Robinson et al., 2007).

The results presented in this paper are unique in that they directly compare fresh particle emissions from a very large sample of light-duty (LD) vehicles and diesel trucks under similar driving conditions, using identical particle analyzers and sampling protocols. Size-segregated particle number emissions $\left(10<\mathrm{D}_{\mathrm{p}}<290 \mathrm{~nm}\right)$ and number concentrations $\left(D_{p}>3 n m\right)$ were measured in a highway tunnel where the aerosol had undergone real-world "tailpipe-to-roadway" dilution (Zhang and Wexler, 2004), but had not further aged in the atmosphere. We report particle number and volume size distributions, size segregated number and volume emission factors (per unit fuel), and total particle number and volume emission factors, separately for LD vehicles and for 
medium- (MD) and heavy-duty (HD) diesel trucks (henceforth referred to as diesel trucks). We also compare results reported here to previous measurements from 1997 (Kirchstetter et al., 1999) at the same site to quantify long-term temporal trends for total particle number emission factors.

\section{Experimental Methods}

\subsection{Field Measurements.}

Emissions from motor vehicles were measured at the Caldecott tunnel on California Highway 24, located in the San Francisco Bay area. The $1 \mathrm{~km}$ long tunnel has 3 separate traffic bores, each with 2 lanes. Measurements were made in 2 of the 3 traffic bores. Bore 1, the southernmost bore, carried a mix of LD vehicles and MD and HD trucks. Vehicles were defined as $\mathrm{LD}=2$-axle/4-tire, $\mathrm{MD}=2$-axle/6-tire, and $\mathrm{HD}=3$ or more axles (BanWeiss et al., 2008). Average traffic flow rates in bore 1 were $1958 \pm 127 \mathrm{LD}$ vehicles $\mathrm{h}^{-1}$, and $153 \pm 9 \mathrm{MD} / \mathrm{HD}$ trucks $\mathrm{h}^{-1}$ from $1200-1400 \mathrm{~h}$. Bore 2 carried mostly LD vehicles $\left(3800 \pm 131 \mathrm{~h}^{-1}\right)$ with a small fraction of MD trucks $(<1 \%)$ from $1600-1800 \mathrm{~h}$. Pollutant concentrations were measured from $1200-1400 \mathrm{~h}$ in the mixed traffic bore to maximize the truck fraction, and from $1600-1800 \mathrm{~h}$ in the LD-only bore to maximize traffic volumes. Traffic was always traveling eastbound and uphill on a $4 \%$ grade. Measurements were made on 8 weekdays in each traffic bore during July and August of 2006 (see Table 1 for exact dates).

Pollutant concentrations were measured simultaneously at the traffic entrance (west end) and exit (east end) of the tunnel. Particle analyzers were located in the exhaust duct 
directly above the traffic. Sample air was carried from the sample inlet, located $\sim 15 \mathrm{~cm}$ below the ceiling of the traffic bore, through approximately $1 \mathrm{~m}$ of conductive silicone tubing to the particle analyzers. An upper size cutoff of $2.5 \mu \mathrm{m}$ was achieved using sharp cut cyclones (BGI, Waltham, MA, model VSCCA). Particle size distributions were measured at each end of the tunnel using TSI (Shoreview, MN) model 3080L scanning mobility particle sizers (SMPS) paired with TSI model 3025A ultrafine condensation particle counters (CPC). This system was configured to measure number concentration as a function of particle size for $10<\mathrm{D}_{\mathrm{p}}<290 \mathrm{~nm}$. Separate standalone CPCs were used to determine total particle number concentrations. An ultrafine water CPC (TSI model 3786) was used to measure particle number concentrations $\left(D_{p}>3 n m\right)$ at the traffic exit, whereas a butanol-based TSI 3022A CPC $\left(D_{p}>7 \mathrm{~nm}\right)$ was used at the traffic entrance. Due to the high particle concentrations inside the tunnel, the CPC sample air at the tunnel exit was diluted prior to being analyzed. The sample line was split into two parallel lines. One line passed through an orifice and the other through a HEPA filter; the lines were recombined prior to passing through the CPC. The pressure drop across the orifice caused a large and stable fraction of the sample flow to pass through the lower pressure drop line where the HEPA filter removed all of the particles. Because 2 different orifices were used throughout the measurement campaign, dilution ratios varied as follows. All measurements in the mixed-traffic bore (bore 1) had a dilution ratio of 15.2. Measurements in the LD-only bore (bore 2) were undiluted except for August 9 and August 10, which had dilution ratios of 7.9 and 15.2, respectively. Particle measurements at the tunnel entrance were not diluted. 
$\mathrm{CO}_{2}$ concentrations were measured using LICOR (Lincoln, NE) model 820 nondispersive infrared gas analyzers at both ends of the tunnel. Concentrations of $\mathrm{CO}$ were measured using gas filter correlation spectrometers (Thermo Environmental Instruments (TEI), Franklin, MA, model 48). These gas-phase analyzers were located in a fan room at the tunnel exit, and in an unoccupied control room at the entrance to the tunnel.

\subsection{Data Analysis.}

Two-hour average particle number concentrations and size distributions were calculated for each sample day in both traffic bores. Particle number emission factors, $\mathrm{E}_{\mathrm{N}}$ (\# of particles emitted per kg fuel burned), were calculated by eq 1 ,

$$
E_{N}=\frac{\Delta[\mathrm{N}]}{\Delta\left[\mathrm{CO}_{2}\right]+\Delta[\mathrm{CO}]} w_{c} \cdot 10^{12}
$$

where $\Delta[\mathrm{N}]$ is the background-subtracted (i.e. tunnel exit - entrance) particle number concentration in units of $\# \mathrm{~cm}^{-3}, \Delta\left[\mathrm{CO}_{2}\right]$ and $\Delta[\mathrm{CO}]$ are background-subtracted concentrations in units of $\mathrm{mg} \mathrm{C} \mathrm{m} \mathrm{m}^{-3}$, and $w_{c}=0.85$ or 0.87 is the mass fraction of carbon in gasoline and diesel fuel, respectively. Size-segregated particle number emission factors, $d \mathrm{E}_{\mathrm{N}} / d \log \mathrm{D}_{\mathrm{p}}$, were calculated by applying eq. 1 separately for each of the 102 particle size bins from the SMPS data $(10-290 \mathrm{~nm}$ size range). Size distributions at the tunnel entrance (background) were measured on 2 days in both bores. The average entrance size distribution for each traffic bore was used for the background subtraction in eq 1 on all days. Note that size distributions reported here are not corrected for particle losses. Given the lower sizecut discrepancy for the tunnel inlet vs. outlet standalone 
CPCs ( 3 vs. $7 \mathrm{~nm}$ ), emission factor results for total particle number may be biased slightly high. However, background concentrations of particles with $3<\mathrm{D}_{\mathrm{p}}<7 \mathrm{~nm}$ are relatively low, making this bias small; further, the emission factor calculation is not very sensitive to background concentration due to the high concentrations at the tunnel outlet.

To calculate LD vehicle emission factors, eq 1 was used directly with pollutant concentrations from the LD-only traffic bore (bore 2). To calculate diesel truck emission factors, pollutant concentrations from the mixed-traffic bore were first apportioned between LD vehicles and diesel trucks as described in detail by Ban-Weiss et al. (2008). Briefly, to carry out this apportionment, observed traffic counts and estimated fuel consumption rates by vehicle category were used to apportion contributions to total $\mathrm{CO}_{2}$ emissions inside the tunnel. Then particle emissions from diesel trucks were estimated by subtracting LD vehicle emissions (measured in bore 2) from totals observed in the mixedtraffic bore (bore 1), as shown in eq 2

$$
\Delta[\mathrm{N}]_{1, \mathrm{D}}=\Delta[\mathrm{N}]_{1}-\Delta\left[\mathrm{CO}_{2}\right]_{1, \mathrm{G}}\left(\frac{\Delta[\mathrm{N}]_{2}}{\Delta\left[\mathrm{CO}_{2}\right]_{2}}\right)
$$

where subscripts D and G indicate diesel and gasoline, subscripts 1 and 2 outside the brackets indicate tunnel bore number, and $\Delta\left[\mathrm{CO}_{2}\right]_{1, \mathrm{G}}$ is the concentration of $\mathrm{CO}_{2}$ in bore 1 attributed to LD vehicles (see eq 3 in Ban-Weiss et al. (2008)). This method was carried out for each of the 102 particle size bins to calculate $d \mathrm{E}_{\mathrm{N}} / d \log \mathrm{D}_{\mathrm{p}}$ for diesel trucks. 
It should be noted that the method for apportioning pollutants in bore 1 (eq 2) has been updated since Kirchstetter et al. (1999). They used the assumption that LD vehicles and HD trucks emit the same amount of $\mathrm{CO}$ per unit distance traveled. This was a valid assumption in 1997, but is now questionable since CO emissions from LD vehicles have decreased more than for HD trucks (Ban-Weiss et al. (2008)). For this reason we updated our apportionment technique to use $\mathrm{CO}_{2}$ as a tracer instead of $\mathrm{CO}$, and have recalculated values from Kirchstetter et al. as presented in the Results and Discussion section of this paper. An added bonus of the updated technique is that emission factor results now depend on the pollutant-to- $-\mathrm{CO}_{2}$ ratio $\left(\Delta[\mathrm{N}]_{2} / \Delta\left[\mathrm{CO}_{2}\right]_{2}\right)$ in bore 2 (see eq 2), and not the pollutant-to-CO ratio $\left(\Delta[\mathrm{N}]_{2} / \Delta[\mathrm{CO}]_{2}\right)$ as in Kirchstetter et al. The pollutant-to- $\mathrm{CO}_{2}$ ratio is more stable throughout the day, as can be observed in Figure 4 by Ban-Weiss et al. (2008).

\section{Results and Discussion}

Figure 1 shows average size distributions for the tunnel exit (east end) and entrance (west end) in both traffic bores. The error bars represent the day-to-day variation $(1 \sigma)$ in 2-hr average size distributions. It can be observed that tunnel exit concentrations are considerably higher than background (entrance) values for all particle diameters shown.

Figure 2 shows (a) number and (b) volume emission factors as a function of particle size separately for LD vehicles and diesel trucks (Table S1 and S2 in the supplemental information contains the data used to create Figure 2). For all particle sizes measured, diesel trucks emit at least an order of magnitude more particles than LD vehicles, per unit 
of fuel burned. The relative importance of $\mathrm{LD}$ vehicles as a source of particle number emissions increases as $D_{p}$ decreases, as has been observed elsewhere (Johnson et al., 2005). This trend could conceivably continue as $D_{p}$ decreases below the lower size cutoff of the size distribution measurements $(10 \mathrm{~nm})$, with the potential for $\mathrm{LD}$ vehicles being responsible for a larger fraction of nuclei mode particles in this size range. Diesel truck emissions have a peak at $D_{p} \sim 16 \mathrm{~nm}$ in the particle number distribution. LD vehicles show a peak in the number distribution slightly higher at $\mathrm{D}_{\mathrm{p}} \sim 22 \mathrm{~nm}$. Figure $2 \mathrm{~b}$ shows a peak in particle volume, and thus PM mass, at $\mathrm{D}_{\mathrm{p}} \sim 150 \mathrm{~nm}$ for $\mathrm{LD}$ vehicles. For diesel trucks, the particle volume emissions appear to be at or near a plateau at $D_{p}=290 \mathrm{~nm}$ where SMPS scans ended. Kleeman et al. (2000) found a single peak in particle mass distributions between $100-200 \mathrm{~nm}$ for both gasoline and diesel vehicles. However, we cannot discount the fact that a second peak may exist at $D_{p}>290 \mathrm{~nm}$.

\subsection{Particle Number Emissions}

Daily 2-hr average particle number concentrations at both ends of the tunnel are shown in Table 1. Number concentrations are shown both from the CPC measurements and from integration of the measured size distributions. CPC-derived number concentrations are generally slightly higher than obtained by integrating the SMPS-derived size distributions likely because the standalone CPC counted particles below the lower limit of the SMPS.

Table 2 shows particle number and volume emission factors. Error bars reflect day-to-day variability ( $95 \%$ confidence interval) in the calculated emission factors. Particle number emission factors were found to differ by up to $\sim 40 \%$ when calculated using results from 
the standalone CPC vs. integrated size distributions from the SMPS. Note however that these differences are not statistically significant with 95\% confidence. Diesel trucks dominate particle number emissions per unit of fuel burned with an emission factor ratio of $8 \pm 5$, calculated using the CPC results.

Particle number emission rates were also measured in the Caldecott tunnel during summer 1997 using a TSI model 3760, which measured particles with $\mathrm{D}_{\mathrm{p}}>10 \mathrm{~nm}$ (Kirchstetter et al., 1999). Note that the diesel truck emission factor for 1997 shown in Table 2 is slightly higher than reported in Kirchstetter et al. due to changes in data analysis methods (see Data Analysis section). There is no statistically significant difference in the diesel/gasoline emission factor ratio for 2006 vs. 1997. Direct comparison between results from 2006 and 1997 is complicated because of the difference in the lower limit of particle sizes measured (10 nm in $1997 \mathrm{vs.} 3 \mathrm{~nm}$ in 2006). However, number emissions were lower in 2006 despite the inclusion of particles in the 3-10 nm range; had the measurements in 2006 and 1997 used the same CPC, the reduction in emission rate would have been greater. The conclusion therefore is that particle number emission rates for both LD vehicles and diesel trucks have decreased since 1997, at least for the vehicle fleets and driving conditions observed at the Caldecott tunnel. Using the values shown in Table 2 from the CPC measurements, number emission factors decreased by $15 \pm 7 \%$ and $54 \pm 33 \%$ between 1997 and 2006 for LD vehicles and diesel trucks, respectively. Given that these percent reductions are lower bounds due to the aforementioned lower size cutoff discrepancy, we can say with 95\% confidence that number concentrations decreased by $>8 \%$ for LD vehicles and $>21 \%$ for diesel trucks. 
This is an interesting result countering a previously suggested hypothesis that diesel engine particle number emissions from new engines may be increasing as mass emissions are decreasing (to meet emissions standards).

In order to facilitate comparison of results to other studies, emission factor size distributions were integrated over select ranges of $D_{p}$ to find number emissions for particles with diameters less than 30,50 , and $100 \mathrm{~nm}\left(\mathrm{~N}_{30}, \mathrm{~N}_{50}\right.$, and $\mathrm{N}_{100}$ respectively). As shown in Table 3, the ratio of particles with $\mathrm{D}_{\mathrm{p}}<30 \mathrm{~nm}$ to total particle number $\left(\mathrm{N}_{30} / \mathrm{N}\right)$ was found to be approximately 0.6 for both LD vehicles and diesel trucks. This indicates that the majority of particles emitted are in the nuclei mode, as expected. Values reported here are slightly lower than reported in Johnson et al. (2005) (see Table 3). $\mathrm{N}_{50} / \mathrm{N}$ and $\mathrm{N}_{100} / \mathrm{N}$ reported in Imhof et al. (2006) for the Plabutsch tunnel are considerably lower than in the present study because of differences in the range of measured particle size (18 - $700 \mathrm{~nm}$ in Imhof et al. vs. $10-290 \mathrm{~nm}$ in the present study).

\subsection{Particle Volume Emissions}

Particle volume emission factors were calculated by integrating the number size

distributions with $\frac{\pi}{6} \mathrm{D}_{\mathrm{p}}{ }^{3}$ weighting (see Figure 2b). As shown in Table 2, the particle volume emission factor was $28 \pm 11$ times larger for diesel trucks than for LD vehicles. This is consistent with the diesel/gasoline emission factor ratio for $\mathrm{PM}_{2.5}$ mass measured using gravimetric analysis of Teflon filters, reported in a companion paper (Ban-Weiss et al., 2008). The diesel/gasoline emission factor ratio is larger for particle volume/mass 
than for number because of the large volume/mass of accumulation mode particles emitted by diesel trucks.

Particle volume emission factors as a function of $D_{p}$ were integrated to find total volumes of particles emitted with diameters less than 30,50 , and $100 \mathrm{~nm}\left(\mathrm{~V}_{30}, \mathrm{~V}_{50}\right.$, and $\mathrm{V}_{100}$ respectively). As shown in Table 3 , the ratios of $\mathrm{V}_{30} / \mathrm{V}$ and $\mathrm{V}_{50} / \mathrm{V}$ were $<0.1$, indicating that the majority of particle volume, and thus mass, is found in the accumulation mode. Kittelson et al. (2006a; 2006b) compared laboratory vs. on-road measurement methods for determining LD vehicle particle emissions. Laboratory results, including an unusually high-emitting vehicle, indicated that $\mathrm{V}_{30} / \mathrm{V}$ was $\sim 0.98$, suggesting that the majority of particulate mass was in the nuclei mode; this fraction was 0.57 excluding the highemitter. On-road results from Kittelson et al., however, agree with the conclusion found in the present study that the majority of particulate volume is in the accumulation mode (see Table 3). Also shown in Table 3 are values reported in Imhof et al. (2006) for the Plabutsch tunnel. Results are not directly comparable to Caldecott tunnel values because of the different particle size ranges measured, leading to the lower values reported in Imhof et al.

\subsection{Comparison to Geller et al. (2005)}

Geller et al. (2005) measured particle mass concentrations and size distributions in the Caldecott tunnel in 2004. Like our study they found that, compared to light-duty vehicles, diesel trucks emitted greater numbers of particles for all sizes measured, with an increase in the fraction from diesel exhaust as $\mathrm{D}_{\mathrm{p}}$ increases. 
To evaluate emissions trends, Geller et al. compared their results to those of Kirchstetter et al. (1999) and came to the conclusion that the number of particles emitted per unit fuel burned by both LD vehicles and HD trucks increased from 1997 to 2004. This conclusion disagrees with our finding that particle number emission factors have decreased since 1997. We note that based on the values reported in Geller et al. (Table 7), their increase in particle number emission factors for diesel trucks is not actually statistically significant. Nonetheless, we suggest that our results are more appropriate to compare to Kirchsetter et al. than those of Geller et al. for the reasons to follow.

Most importantly, like Kirchstetter et al., we directly measured total particle number concentrations using standalone CPCs, whereas Geller et al. measured total number concentrations indirectly by integrating size distributions measured with an SMPS. These two methods were compared in our study and were found to lead to discrepancies of up to $\sim 40 \%$ in emission factors (see Table 2). The exact discrepancies caused by the different methodologies of Geller et al. and Kirchstetter et al. are unknown since they used different models of the SMPS and CPC than we used to make this method comparison. But the discrepancies are expected to be nontrivial. Our study uses known differences in the ability of the CPCs to measure the smallest particles to report a lower bound estimate of particle number emissions reductions since 1997.

Another issue is that in the study of Geller et al. and Kirchstetter et al., pollutants in bore 1 were apportioned using $\mathrm{CO}$ as a tracer, which assumes that $\mathrm{CO}$ emissions per unit 
distance traveled are the same for LD vehicles and diesel trucks. As described in BanWeiss et al. (2008), CO emissions from LD vehicles have decreased more than for diesel trucks since 1997, and thus this assumption has become less accurate in the last decade. Therefore, a better approach for apportioning emissions from the current fleet is to use $\mathrm{CO}_{2}$ as a tracer as used in our study. While at face value it seems that Geller et al. is more consistent with Kirchstetter et al. since they both used $\mathrm{CO}$ as a tracer, we suggest that the revised apportionment technique provides more accurate results leading to a better estimate in emissions trends since 1997. Note that we have recalculated results from Kirchstetter et al. using $\mathrm{CO}_{2}$ as a tracer (see Table 2) to ensure that our reported emission factor reductions are due only to emissions changes, and not differences in the apportionment technique.

\section{Summary and Conclusions}

Particulate emissions of $\sim 61000$ LD vehicles, $\sim 1600$ MD trucks, and $\sim 900$ HD trucks were measured on-road in a San Francisco Bay area highway tunnel. By measuring in two traffic bores (one with mixed traffic and one with only LD vehicles) using identical instrumentation and measurement protocol, pollutants were apportioned between LD vehicles and MD and HD diesel trucks to directly compare the relative importance each of these sources per unit of fuel as a function of particle size.

We found that for both LD vehicles and diesel trucks, the majority of particles by number were emitted in the nuclei mode, whereas the majority of particles by volume (and thus mass) were emitted in the accumulation mode, as expected. Diesel trucks were 
responsible for at least an order of magnitude more particles by number for all sizes measured $\left(10<D_{p}<290 \mathrm{~nm}\right)$ per unit fuel burned. The relative importance of LD gasoline vehicles as a source of particles increased as $\mathrm{D}_{\mathrm{p}}$ decreased, and thus should not be discounted as a source of nuclei mode particles. It is possible that LD vehicles were responsible for a greater fraction of nuclei mode particles than diesel trucks below the lower limit of the size distribution measurements $\left(D_{p}<10 \mathrm{~nm}\right)$.

Particle number emissions per unit fuel measured directly using a standalone $C P C\left(D_{p}>\right.$ $3 \mathrm{~nm}$ ) were found to be $8 \pm 5$ times higher for diesel trucks than LD vehicles. Calculating the same quantity by integrating size distributions resulted in a number emission factor ratio of $14 \pm 4$. Particle number emission factors were found to differ by up to $\sim 40 \%$ when calculated using results from the standalone CPC vs. integrated size distributions from the SMPS (see Table 2). Integrating the size distributions with a volume weighting showed that diesel trucks emitted $28 \pm 11$ times more particles by volume than LD vehicles. This is consistent with the diesel/gasoline emission factor ratio for $\mathrm{PM}_{2.5}$ mass measured using gravimetric analysis of Teflon filters, reported in a companion paper (Ban-Weiss et al., 2008).

Results reported in the current study were compared to similar measurements at the same site from 1997 (Kirchstetter et al., 1999). It was found with 95\% confidence that particle number emission factors decreased by at least $8 \%$ and $21 \%$ for LD vehicles and diesel trucks, respectively, from 1997 to 2006 . The reductions may have been larger than these values because the CPC used in 1997 measured particles with $D_{p}>10 \mathrm{~nm}$, whereas the 
CPC used in 2006 measured particles with $D_{p}>3 \mathrm{~nm}$. The observed decrease in particle number emissions contradicts a previous assertion that diesel engine particle number emissions from new engines may be increasing as mass emissions are decreasing (to meet emissions standards).

The particles characterized in this study underwent real-world "tailpipe-to-road" dilution (Zhang and Wexler, 2004). Thus, results are most applicable to assessment of the relative importance of LD vehicles vs. diesel trucks to near-source human exposure. Since the aerosol had not undergone "road-to-ambient" aging (Zhang and Wexler, 2004), results reported here should not be used directly to interpret climatic effects, which change as the particles evolve in size and composition in the atmosphere (Seigneur, 2009).

Recent studies have suggested that the use of diesel particulate filters (DPF), though effective at reducing particulate mass emissions, may under certain conditions actually increase particle number concentrations (Seigneur, 2009). Since measurements reported here were made in 2006 prior to widespread deployment of DPFs on new HD trucks, this investigation can serve as a baseline for future studies to quantify effects of DPFs on particle number emission factors and size distributions. 


\section{Acknowledgments}

The authors would like to thank John McLaughlin, Andrew Kean, Tony Strawa, Susanne Hering, and the staff of the Bay Area Air Quality Management District for their assistance. Thanks also to the Caltrans staff at the Caldecott tunnel. This research was supported by the California Air Resources Board under contract no. 05-309. The statements and conclusions herein are those of the authors and do not necessarily reflect the views of the project sponsor. LBNL authors Lunden and Kirchstetter were also supported by the Director, Office of Science, Office of Basic Energy Sciences, of the U.S. Department of Energy under Contract No. DE-AC02-05CH11231. 


\section{References}

Ayala, A., Olson, B., Cantrell, B., Drayton, M., Barsic, N., 2003. Estimation of diffusional losses when sampling diesel aerosol: A quality assurance measure. Society of Automotive Engineers 2003-01-1896.

Ban-Weiss, G.A., Lunden, M.M., Kirchstetter, T.W., Harley, R.A., 2009. Measurement of black carbon and particle number emission factors from individual heavy-duty trucks. Environmental Science \& Technology 43, 1419-1424.

Ban-Weiss, G.A., McLaughlin, J.P., Harley, R.A., Lunden, M.M., Kirchstetter, T.W., Kean, A.J., Strawa, A.W., Stevenson, E.D., Kendall, G.R., 2008. Long-term changes in emissions of nitrogen oxides and particulate matter from on-road gasoline and diesel vehicles. Atmospheric Environment 42, 220-232.

Donaldson, K., Beswick, P.H., Gilmour, P.S., 1996. Free radical activity associated with the surface of particles: A unifying factor in determining biological activity? Toxicology Letters 88, 293-298.

Geller, V.D., Sardar, S.B., Phuleria, H., Fine, P.N., Sioutas, C., 2005. Measurements of particle number and mass concentrations and size distributions in a tunnel environment. Environmental Science \& Technology 39, 8653-8663.

Graskow, B., Kittelson, D.B., Abdul-Khalek, I.S., Ahmadi, M.R., Morris, J.E., 1998. Characterization of exhaust particulate emissions from a spark ignition engine. Society of Automotive Engineers 980528.

Imhof, D., Weingartner, E., Prevot, A.S.H., Ordonez, C., Kurtenbach, R., Wiesen, P., Rodler, J., Sturm, P., McCrae, I., Ekstrom, M., Baltensperger, U., 2006. Aerosol and NOx emission factors and submicron particle number size distributions in two 
road tunnels with different traffic regimes. Atmospheric Chemistry and Physics 6, 2215-2230.

Johnson, J.P., Kittelson, D.B., Watts, W.F., 2005. Source apportionment of diesel and spark ignition exhaust aerosol using on-road data from the Minneapolis metropolitan area. Atmospheric Environment 39, 2111-2121.

Kayes, D., Hochgreb, S., Maricq, M.M., Podsiadlik, D.H., Chase, R.E., 2000. Particulate matter emissions during start-up and transient operation of a spark-ignition engine (2): Effect of speed, load, and real-world driving cycles. Society of Automotive Engineers 2000-01-1083.

Kennedy, I.M., 2007. The health effects of combustion-generated aerosols. Proceedings of the Combustion Institute 31, 2757-2770.

Kirchstetter, T.W., Harley, R.A., Kreisberg, N.M., Stolzenburg, M.R., Hering, S.V., 1999. On-road measurement of fine particle and nitrogen oxide emissions from light- and heavy-duty motor vehicles. Atmospheric Environment 33, 2955-2968.

Kittelson, D.B., 1998. Engines and nanoparticles: A review. Journal of Aerosol Science $29,575-588$.

Kittelson, D.B., Watts, W.F., Johnson, J.P., 2006a. On-road and laboratory evaluation of combustion aerosols - Part 1: Summary of diesel engine results. Journal of Aerosol Science 37, 913-930.

Kittelson, D.B., Watts, W.F., Johnson, J.P., Schauer, J.J., Lawson, D.R., 2006b. On-road and laboratory evaluation of combustion aerosols - Part 2: Summary of spark ignition engine results. Journal of Aerosol Science 37, 931-949. 
Kleeman, M.J., Schauer, J.J., Cass, G.R., 2000. Size and composition distribution of fine particulate matter emitted from motor vehicles. Environmental Science \& Technology 34, 1132-1142.

Maricq, M.M., Podsiadlik, D.H., Chase, R.E., 1999a. Examination of the size-resolved and transient nature of motor vehicle particle emissions. Environmental Science \& Technology 33, 1618-1626.

Maricq, M.M., Podsiadlik, D.H., Chase, R.E., 1999b. Gasoline vehicle particle size distributions: Comparison of steady state, FTP, and US06 measurements. Environmental Science \& Technology 33, 2007-2015.

Pope, C.A., Dockery, D.W., 2006. Health effects of fine particulate air pollution: Lines that connect. Journal of the Air \& Waste Management Association 56, 709-742.

Pope, C.A., Thun, M.J., Namboodiri, M.M., Dockery, D.W., Evans, J.S., Speizer, F.E., Heath, C.W., 1995. Particulate air-pollution as a predictor of mortality in a prospective-study of US adults. American Journal of Respiratory and Critical Care Medicine 151, 669-674.

Ramanathan, V., Carmichael, G., 2008. Global and regional climate changes due to black carbon. Nature Geoscience 1, 221-227.

Robinson, A.L., Donahue, N.M., Shrivastava, M.K., Weitkamp, E.A., Sage, A.M., Grieshop, A.P., Lane, T.E., Pierce, J.R., Pandis, S.N., 2007. Rethinking organic aerosols: Semivolatile emissions and photochemical aging. Science 315, 12591262.

Seaton, A., Macnee, W., Donaldson, K., Godden, D., 1995. Particulate air-pollution and acute health-effects. Lancet 345, 176-178. 
Seigneur, C., 2009. Current understanding of ultrafine particulate matter emitted from mobile sources. Journal of the Air \& Waste Management Association 59, 3-17.

Zhang, K.M., Wexler, A.S., 2004. Evolution of particle number distribution near roadways - Part I: analysis of aerosol dynamics and its implications for engine emission measurement. Atmospheric Environment 38, 6643-6653. 


\section{Figure Captions}

Figure 1. Average particle size distributions measured at both ends of the (a) LD-only bore (bore 2) and (b) mixed traffic bore (bore 1). Error bars represent the day-to-day variation $(1 \sigma)$ in 2-hr average size distributions.

Figure 2. Size-resolved emission factors for (a) particle number and (b) volume. Error bars represent day-to-day variability (95\% confidence interval) in the calculated emission factors for each size bin. 
Table 1. Measured 2-hour average particle number concentrations

\section{Bore 1}

\begin{tabular}{|c|c|c|c|}
\hline Date & Location & $\begin{array}{c}\mathrm{CPC}^{\mathrm{a}, \mathrm{c}} \\
\#_{\mathrm{cm}^{-3}}\end{array}$ & $\begin{array}{c}\text { SMPS }^{b, c} \\
\#^{-3}{ }^{-3}\end{array}$ \\
\hline \multirow[t]{2}{*}{ Tue, Jul 18} & East & $2.40 \times 10^{5}$ & $2.41 \times 10^{5}$ \\
\hline & West & $8.11 \times 10^{4}$ & \\
\hline \multirow[t]{2}{*}{ Wed, Jul 19} & East & $4.17 \times 10^{5}$ & $1.82 \times 10^{5}$ \\
\hline & West & $1.09 \times 10^{5}$ & \\
\hline \multirow[t]{2}{*}{ Thu, Jul 20} & East & $3.02 \times 10^{5}$ & $1.75 \times 10^{5}$ \\
\hline & West & $7.71 \times 10^{4}$ & $2.96 \times 10^{4}$ \\
\hline \multirow[t]{2}{*}{ Fri, Jul 21} & East & $3.35 \times 10^{5}$ & $1.93 \times 10^{5}$ \\
\hline & West & $1.04 \times 10^{5}$ & $3.51 \times 10^{4}$ \\
\hline \multirow[t]{2}{*}{ Mon, Jul 24} & East & $2.65 \times 10^{5}$ & $2.67 \times 10^{5}$ \\
\hline & West & $8.27 \times 10^{4}$ & \\
\hline \multirow[t]{2}{*}{ Tue, Jul 25} & East & $2.11 \times 10^{5}$ & $2.75 \times 10^{5}$ \\
\hline & West & $1.07 \times 10^{5}$ & \\
\hline \multirow[t]{2}{*}{ Wed, Jul 26} & East & $2.63 \times 10^{5}$ & $2.31 \times 10^{5}$ \\
\hline & West & $8.39 \times 10^{4}$ & \\
\hline \multirow[t]{2}{*}{ Thu, Jul 27} & East & $2.60 \times 10^{5}$ & $2.66 \times 10^{5}$ \\
\hline & West & $6.86 \times 10^{4}$ & \\
\hline \multirow[t]{2}{*}{ Mean \pm Stnd Dev } & East & $(2.87 \pm 0.66) \times 10^{5}$ & $(2.29 \pm 0.41) \times 10^{5}$ \\
\hline & West & $(8.92 \pm 1.53) \times 10^{4}$ & \\
\hline
\end{tabular}




\section{Table 1 Continued}

\section{Bore 2}

\begin{tabular}{|c|c|c|c|}
\hline Date & Location & $\begin{array}{c}\mathrm{CPC}^{\mathrm{a}, \mathrm{c}} \\
\# \mathrm{~cm}^{-3}\end{array}$ & $\begin{array}{c}\text { SMPS }^{b, c} \\
\# \mathrm{~cm}^{-3}\end{array}$ \\
\hline \multirow[t]{2}{*}{ Mon, Jul 31} & East & $1.77 \times 10^{5}$ & $1.46 \times 10^{5}$ \\
\hline & West & $3.75 \times 10^{4}$ & \\
\hline \multirow[t]{2}{*}{ Tue, Aug 01} & East & $1.60 \times 10^{5}$ & $1.04 \times 10^{5}$ \\
\hline & West & $3.78 \times 10^{4}$ & \\
\hline \multirow[t]{2}{*}{ Wed, Aug 02} & East & $1.60 \times 10^{5}$ & $1.43 \times 10^{5}$ \\
\hline & West & $3.36 \times 10^{4}$ & \\
\hline \multirow[t]{2}{*}{ Thu, Aug 03} & East & $1.48 \times 10^{5}$ & $1.28 \times 10^{5}$ \\
\hline & West & $2.93 \times 10^{4}$ & \\
\hline \multirow[t]{2}{*}{ Mon, Aug 07} & East & & $1.34 \times 10^{5}$ \\
\hline & West & & \\
\hline \multirow[t]{2}{*}{ Tue, Aug 08} & East & $1.61 \times 10^{5}$ & $1.30 \times 10^{5}$ \\
\hline & West & $3.55 \times 10^{4}$ & \\
\hline \multirow[t]{2}{*}{ Wed, Aug 09} & East & $2.60 \times 10^{5}$ & $1.32 \times 10^{5}$ \\
\hline & West & $2.73 \times 10^{4}$ & $1.69 \times 10^{4}$ \\
\hline \multirow[t]{2}{*}{ Thu, Aug 10} & East & $3.04 \times 10^{5}$ & $1.20 \times 10^{5}$ \\
\hline & West & $3.36 \times 10^{4}$ & $1.72 \times 10^{4}$ \\
\hline \multirow[t]{2}{*}{ Mean \pm Stnd Dev } & East & $(1.96 \pm 0.61) \times 10^{5}$ & $(1.30 \pm 0.13) \times 10^{5}$ \\
\hline & West & $(3.35 \pm 0.40) \times 10^{4}$ & \\
\hline
\end{tabular}

${ }^{a}$ Measurements were made with a water-based $C P C\left(D_{p}>3 n m\right)$ at the exit (east end), and a butanol-based CPC $\left(\mathrm{D}_{\mathrm{p}}>7 \mathrm{~nm}\right)$ at the entrance (west end) of the tunnel

${ }^{\mathrm{b}}$ Size distributions were integrated from $10<\mathrm{D}_{\mathrm{p}}<290 \mathrm{~nm}$

${ }^{\mathrm{c}}$ Blank entries indicate that the measurement was not made 
Table 2. Particle number and volume emission factors measured by the CPC and SMPS.

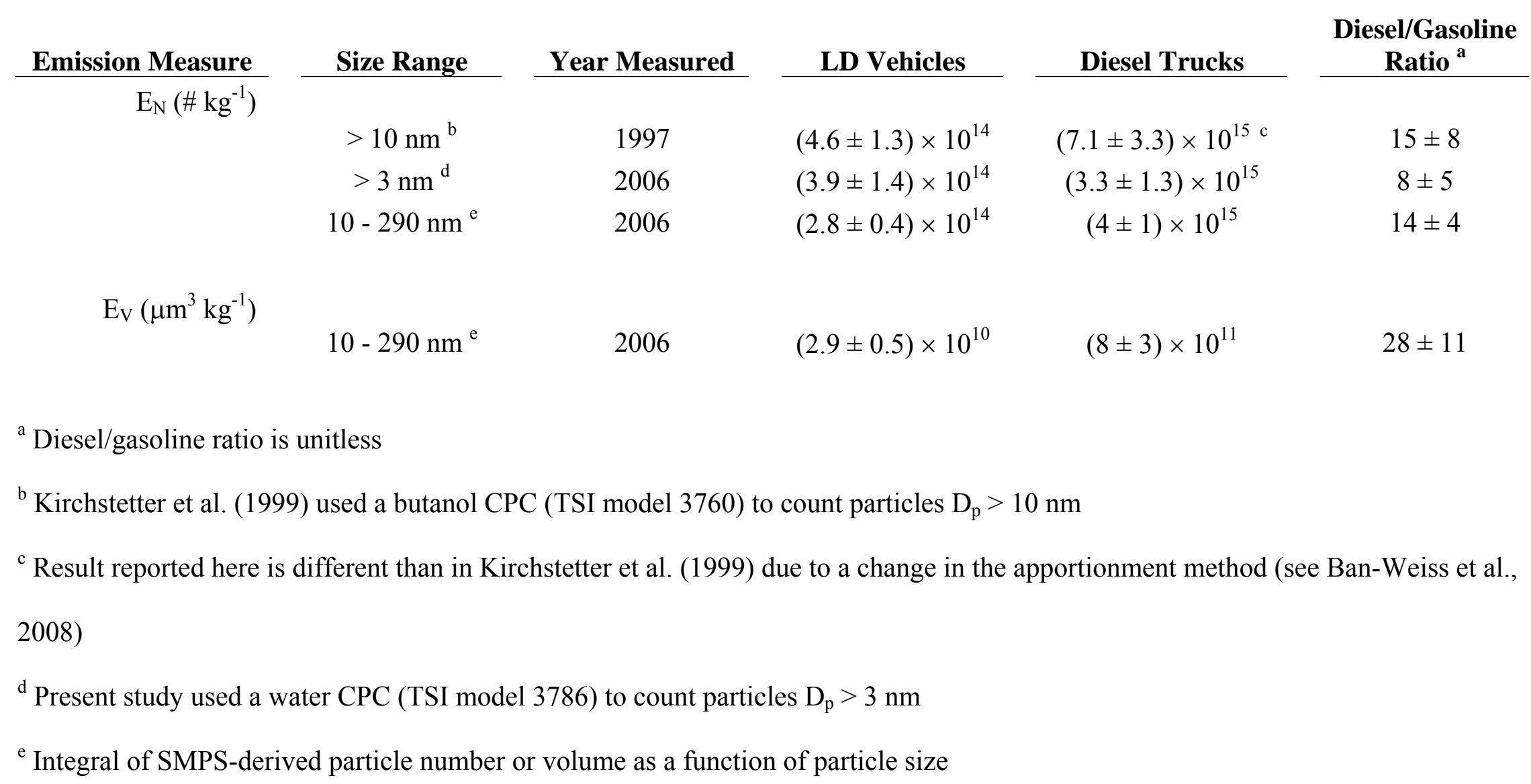


Table 3. Comparison of $\mathrm{N}_{\mathrm{x}} / \mathrm{N}$ and $\mathrm{V}_{\mathrm{x}} / \mathrm{V}$ to other studies. This represents the fraction of particle number and volume to total measured particles that have $\mathrm{D}_{\mathrm{p}}<\mathrm{x}$ m. Note that these ratios are highly dependent on lower and upper size cutoffs (see footnotes).

\section{LD Vehicle}

\begin{tabular}{|c|c|c|c|c|c|c|c|c|}
\hline & This study ${ }^{a}$ & $\begin{array}{l}\text { Johnson et } \\
\text { al., } 2005^{\text {b }}\end{array}$ & 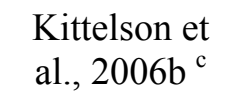 & $\begin{array}{l}\text { Imhof et al., } \\
2006^{\mathrm{d}, \mathrm{e}}\end{array}$ & This study $^{\text {a }}$ & $\begin{array}{c}\text { Johnson et al., } \\
2005^{\mathrm{b}}\end{array}$ & 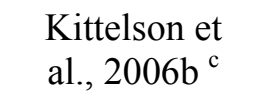 & $\begin{array}{l}\text { Imhof et al., } \\
2006^{\mathrm{d}, \mathrm{e}}\end{array}$ \\
\hline $\mathrm{N}_{30} / \mathrm{N}$ & $0.61 \pm 0.05$ & $0.77 \pm 0.09$ & $0.62 \pm 0.17$ & & $0.58 \pm 0.06$ & $0.76 \pm 0.13$ & \multicolumn{2}{|l|}{$0.74-0.83^{f}$} \\
\hline $\mathrm{N}_{50} / \mathrm{N}$ & $0.80 \pm 0.04$ & & & $0.2 \pm 0.1$ & $0.74 \pm 0.04$ & & & $0.39 \pm 0.07$ \\
\hline $\mathrm{N}_{100} / \mathrm{N}$ & $0.96 \pm 0.01$ & & & $0.6 \pm 0.2$ & $0.91 \pm 0.02$ & & & $0.7 \pm 0.1$ \\
\hline $\mathrm{V}_{30} / \mathrm{V}$ & $0.027 \pm 0.007$ & $0.059 \pm 0.017$ & $0.022 \pm 0.007$ & & $0.012 \pm 0.003$ & $0.008 \pm 0.002$ & \multicolumn{2}{|l|}{$0.007-0.015^{\mathrm{f}}$} \\
\hline $\mathrm{V}_{50} / \mathrm{V}$ & $0.09 \pm 0.02$ & & & $0.004 \pm 0.002$ & $0.035 \pm 0.005$ & & & $\begin{array}{c}0.0050 \pm \\
0.0008\end{array}$ \\
\hline $\mathrm{V}_{100} / \mathrm{V}$ & $0.36 \pm 0.03$ & & & $0.09 \pm 0.02$ & $0.20 \pm 0.02$ & & & $0.044 \pm 0.006$ \\
\hline $\begin{array}{l}{ }^{a} 10<D \\
b^{b} 10<D \\
\text { mobile } \\
\text { c } 8<D_{p} \\
\text { d } 18<D \\
{ }^{2} \text { Direct } \\
\text { f } \\
\text { This re }\end{array}$ & $\begin{array}{l}<290 \mathrm{~nm} \text {. Un } \\
<300 \mathrm{~nm} \text {. Ur } \\
\text { emissions lab } \\
283 \mathrm{~nm} \text {. Unc } \\
<700 \mathrm{~nm} \text {. Ur } \\
\text { omparison of } \\
\text { resents the rat }\end{array}$ & $\begin{array}{l}\text { certainty estir } \\
\text { certainty estir } \\
\text { ratory (MEL } \\
\text { ertainty estim } \\
\text { certainty estir } \\
\text { his study to tl } \\
\text { ge of values }\end{array}$ & $\begin{array}{l}\text { lates are } 95 \% \\
\text { lates are stand } \\
\text { tes are standa } \\
\text { lates are } 95 \% \\
\text { e others is mis }\end{array}$ & $\begin{array}{l}\text { I. Measured } \\
\text { ard deviations } \\
\text { d deviations o } \\
\text { I. Measured } \\
\text { leading becau } \\
\text { riety of cruis }\end{array}$ & $\begin{array}{l}\text { Caldecott tun } \\
\text { e mean. Meas } \\
\text { mean. Measu } \\
\text { Plabutsch tur } \\
\text { the difference } \\
\text { acceleration }\end{array}$ & $\begin{array}{l}\text { on-road using } \\
\text { on-road using } \\
\text { neasured size } 1 \\
\text { litions }\end{array}$ & $\begin{array}{l}\text { University of } \\
\text { MEL } \\
\text { ange }\end{array}$ & linnesota \\
\hline
\end{tabular}



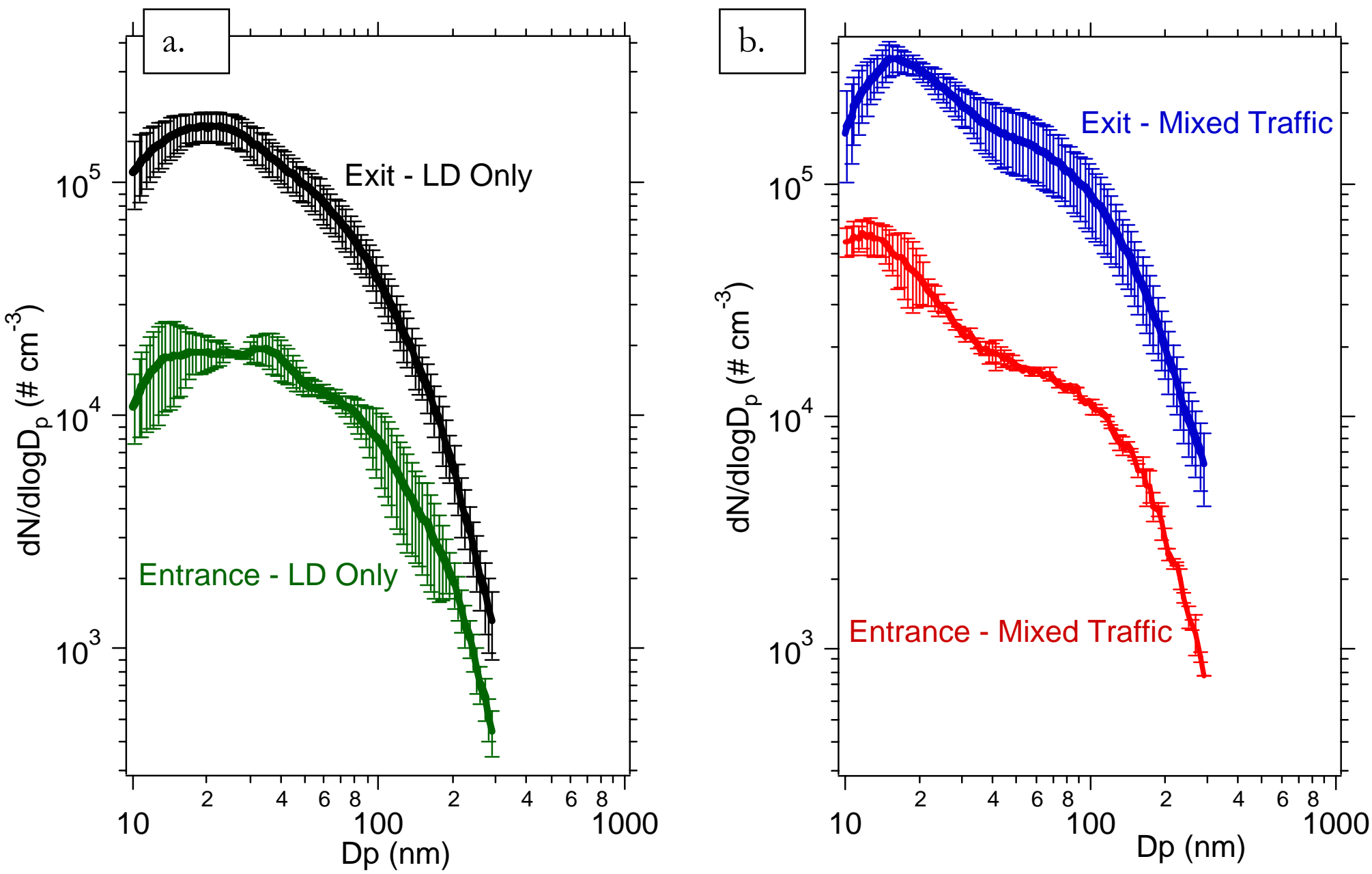

Figure 1. Average particle size distributions measured at both ends of the (a) LD-only bore (bore 2) and (b) mixed traffic bore (bore 1). Error bars represent the day-to-day variation $(1 \sigma)$ in 2 -hr average size distributions. 

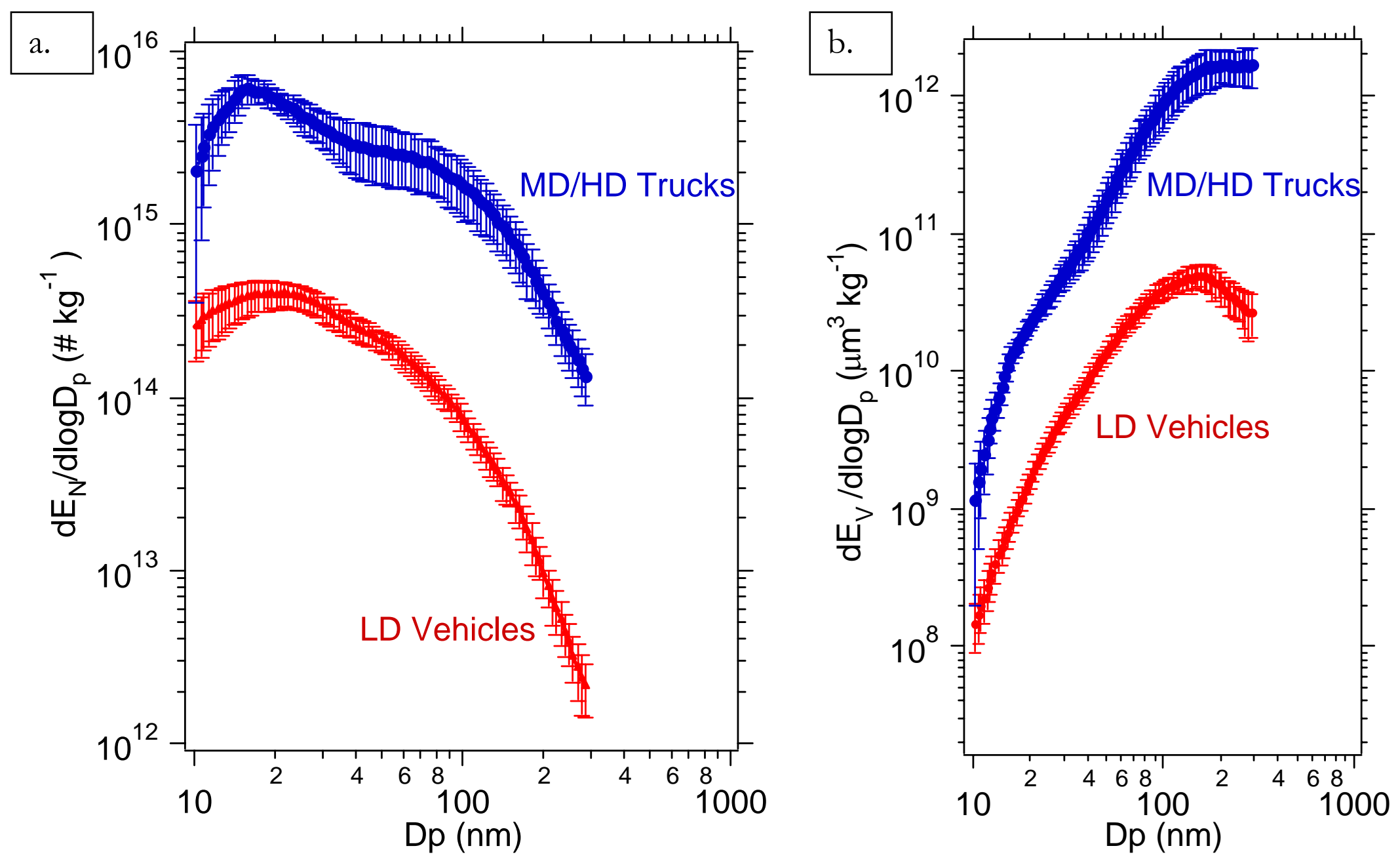

Figure 2. Size-resolved emission factors for (a) particle number and (b) volume. Error bars represent day-to-day variability (95\% confidence interval) in the calculated emission factors for each size bin. 